\title{
GSM Based Home Safety and Security System
}

\author{
Md. Abdullah Al Rakib, Md. Moklesur Rahman, Md. Sohel Rana, \\ Md. Sanjib Islam, and Fysol Ibna Abbas
}

\begin{abstract}
In this paper, we worked on how to control home apparatuses, safety, and security systems utilizing GSM innovation by utilizing a cell phone. We will likewise show that we can control the apparatuses even without a phone by sending an ordinary call. The favorable position of utilizing GSM innovation is that we can handle home appliances from any place in the world. This system permits the proprietor to control the appliances and to get a feedback status of the home apparatuses by sending calls just as through a portable application. For the home security system, we are utilizing an antitheft announcing system that will report the proprietor by sending a message and ringing a call. Likewise, for the security system, when fire or gas spillage is expected to occur, it will also report the proprietor by sending a call. Subsequently, by utilizing GSM innovation, it gives remote access to the gadgets to be controlled.
\end{abstract}

Keywords - Home Security, GSM network, feedback call, GPS module, alarm system, relay module.

\section{INTRODUCTION}

Remote correspondence is expanding step by step. This has propelled us to utilize cell phones to distantly control family unit appliances and to get feedback CALL about the security and wellbeing of the house. Throughout the previous few years, home protection is a fundamental requirement for family units to maintain their homes secure from collisions in order to split up. So the analysts and organizations attempt to execute calculations and make some gradates that keep your home protected from gatecrashers. It is useful in places where we need to monitor the ON and OFF exchange of the gadgets since it is always regulated from any point in the world without a wired association between the switch and the equipment [1].

The microcontroller would then control the home apparatuses dependent on the data given to it and send input during a security break and it likewise sends feedback during gas spillage or if a fire happens [2]. The WSN (Wireless Sensor Network) innovation additionally has the upside of wide covering territory which guarantees distant checking and quick network foundation with sensible cost. The critical distinction between WSN and GSM is its wide inclusion region which encourages exceptionally significant distance correspondence [3]. Describes the working structure and recreation of a GSM-based distant detecting and appliance control utilizing FPGA. Describes the home mechanization measure utilizing speech recognition, GSM, and the web. In this paper, the work primarily centers around the security of the home when the user is out of the spot. GSM-based

Submitted on August 31, 2021.

Published on September 28, 2021.

Md Abdullah Al Rakib

Md. Moklesur Rahman

Md. Sohel Rana innovation proposed to keep refreshed proprietors about house security. SMS bases this protection framework and sends SMS to the owner using creativity from GSM. Typically, the point of this sort of system is to keep the safe home from gatecrashers [4].

The GSM network has been isolated into three expansive parts. The left part incorporates the Mobile Station is conveyed by the endorser, at that point, the Base Station Subsystem controls the radio connection with the Mobile Station. Lastly, the Network of the subsystem, the primary piece of which is known as the Mobile administrations Switching Focus, accomplishes crafted by exchanging of calls between the portable and other fixed or then again versatile organization clients, alongside the board of mobile services, such as confirmation [5]. A lot of testing has been conducted in various Home Monitoring technologies, such as home security based sensors. The system, Figure print, Palm print, and keypad actuation for validation are thus much. All kind of Security system utilizes just a strategy of the GSM module [6].

Among the cell innovations, the GSM network is favored for the correspondence between the home apparatuses, what's more, the user because of its boundless inclusion which makes the entire system online practically constantly. Another preferred position of utilizing the GSM network in home mechanization is its high-security system, which gives the greatest unwavering quality whereby others can't screen the data sent or got. Henceforth, this examination work actualizes SMS-based control for home apparatuses utilizing the GSM design without getting to the nearby network [7].

The "GSM-based control unit" project aims to develop a control device that enables complete device access, because as the title implies. The project's broad goals are a. to use Short Message Service (SMS) to organize appliances and other gadgets; $b$. to efficiently receive and transfer data through SMS, and c. to remove the need to be bodily existing in either position for activities requiring the operation of appliances in a home or workplace. d. Cut back on excess electricity and time. The cell phones and the control unit would be two separate devices in the control system. As a result, two operating environments will be available [8]-[12].

\section{LITERATURE REVIEW}

Research considering Android interface-based GSM home safety system was done by Sharma, Rupam Kumar, where the researcher has researched a low-cost GSM based smart home based security method along with the face recognition 
and detection technique [13]. Another work was developed to stop the access of illegal persons into our home by using facial recognition. The project objective is to monitor and track whether the person is authorized or not was done by Budijono, Santoso, Jeffri Andrianto, and Muhammad Axis Novradin Noor [14]. Another group of researchers has added a vibration sensor to the system. This method contains 89S52 microcontroller board, IR sensor module, Wireless camera to capture the image of a person which was done by Choudhury, Biplav [15]. Another work that developed the system more upgraded, systematic, and effective with electronic door lock arrangement was done by Azid, Sheikh Izzal, and Sushil Kumar [16]. Another group researched a low-cost, highly configurable, and mobile home security system that secures homes from illegal entities attempting to gain illegal entry into such homes which was done by Lee, Jer-Vui, Yea-Dat Chuah, and Chin-Tin Chai. So, in our paper Arduino and GSM based home based safety system was developed which has more sensitivity and we have generated a new proposed model to ensure home security by alarm and calling system together that will be very effective for our future work [17].

\section{DESIGN OF HOMEBASED SAFETY AND SECURITY SYSTEM}

A GSM modem is a special modem that recognizes a SIM card and is similar to a cell phone to a mobile operator. The GSM modem looks just the same as a cell phone from the point of view of the smartphone operating system [18]. In the case of a GSM modem connected to a PC, the PC uses the GSM modem to communicate through the mobile network. Although these GSM modems are used to provide mobile web connectivity as much as possible, a large number of modems may also be used for SMS and MMS calls. A GSM modem may be a committed modem gadget with a series, USB, or Bluetooth association, or a cell phone with the ability to use a GSM modem [19].

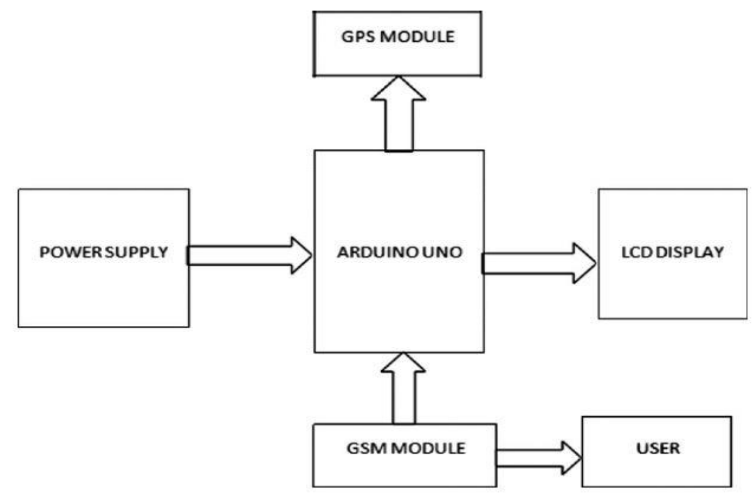

Fig. 1. Block diagram of the prototype.

A buzzer or beeper is an electronic, electromechanical, or piezoelectric device a flagging instrument (piezo for short). Normal use of ringers and beepers involves alarm gadgets, clocks, and consumer details confirmation, such as a mouse snap or keystroke. Here, the CZN-15E Speaker Capacitive $9 \times 7 \mathrm{~mm}$ buzzer was used. A mobile Phone Vibrator Motor was used as well [20].

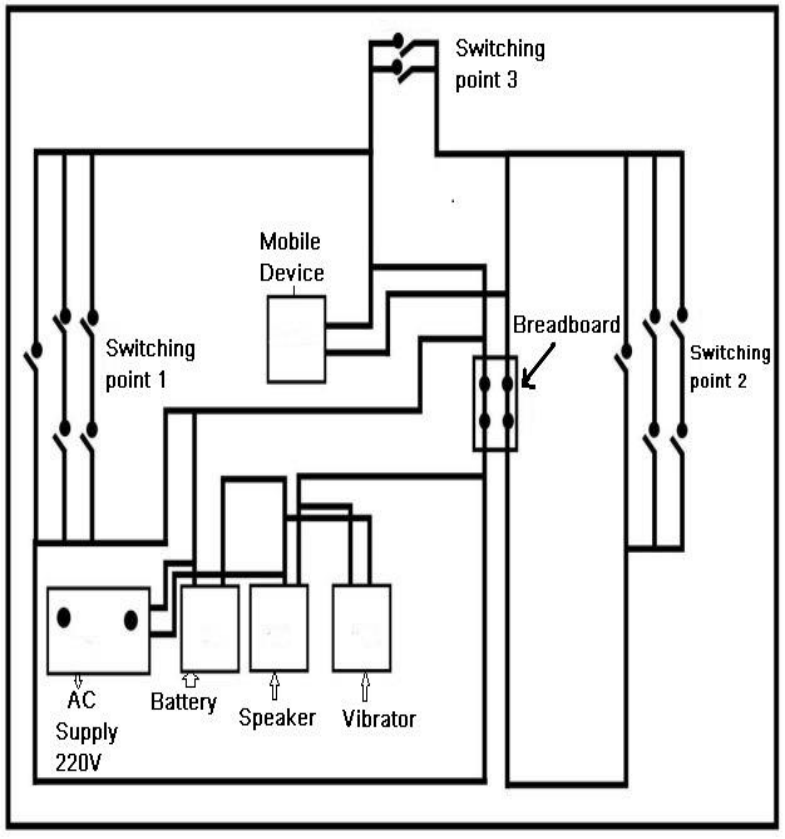

Fig. 2. Circuit diagram of GSM layout.

It is ready to coordinate all operations. The format ought to be planned to yield into account the connections between different hardware, offices, and personnel. It is accordingly significant that while arranging the format the total picture of the association is thought of.

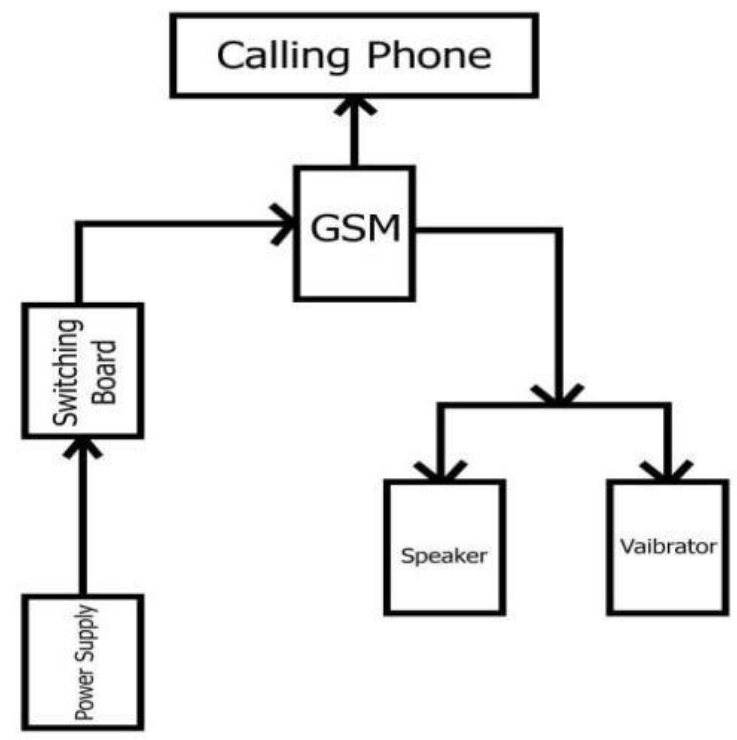

Fig. 3. Block diagram of GSM module.

The diagram of the system in which the chief parts or capacities are spoken to by blocks is associated with lines that show the connections of the blocks. They are vigorously utilized in designing equipment plans, electronic plans, programming plans, and cycle flow graphs. Home mechanization, primary care, and protection framework are the three parts that make up the undertaking's operation. We have planned an android program to manage domestic appliances for home computerization. The use of this program is to give a CALL to our GSM modem. This checks the CALL and transmits it to the microcontroller. The microcontroller extracts the response from the CALL 
received and activates the relay module. The relay module triggers or disables the equipment at the order of the user. If an interloper flows between the two points, the space among them will reduce at this point. The distance feedback is relayed to the microcontroller. The microcontroller would send an input SMS to the proprietor via a GSM modem, and it would also sound an alarm. The benefit of using this safety and protection method is that the basic range at which the caution rings and CALL is sent in client specified, allowing the client to pick any range to which the microcontroller can report [21-23].

\section{A. Charger Circuit}

When we link our charger to a $220 \mathrm{~V} \mathrm{AC}$ power source directly from the switchboard, the charger's first task is to move down the heavy $220 \mathrm{~V}$ to $9 \mathrm{~V}$ (or $10 \mathrm{~V}$ in some cases). Main and secondary coils in a transformer step up or down the voltage depending on the amount of turns in the coils. It is significant to pick the correct transformer. The current ranking is strongminded by the load circuit's current requirement (circuit which will use the generate DC).

A Shifted Mode Power Supply, or SMPSU, is what a Handheld Battery Adapter is. It supplies the Battery with a Constant Voltage (CV) and Constant Current (CC), giving it the energy it requires to charge. The voltage is usually $5 \mathrm{~V}$ $\mathrm{DC}$, and the current is $0.5 \mathrm{~A}$ or $1 \mathrm{~A}$.

zIt operates by taking the $220 / 110 \mathrm{~V}$ AC from the wall socket, rectifying and converting it to DC voltage, filtering it, and moving it via a High Frequency (normally $>20 \mathrm{Khz}$ ) Semiconductor switch, such as a MOSFET or BJT. This high-frequency current is pumped into a Transformer that is much smaller than its $50 / 60 \mathrm{~Hz}$ equivalent. Due to HighFrequency Switching, this size is feasible. The minor side of the Transformer's voltage is first rectified and filtered before being used as an output [24].

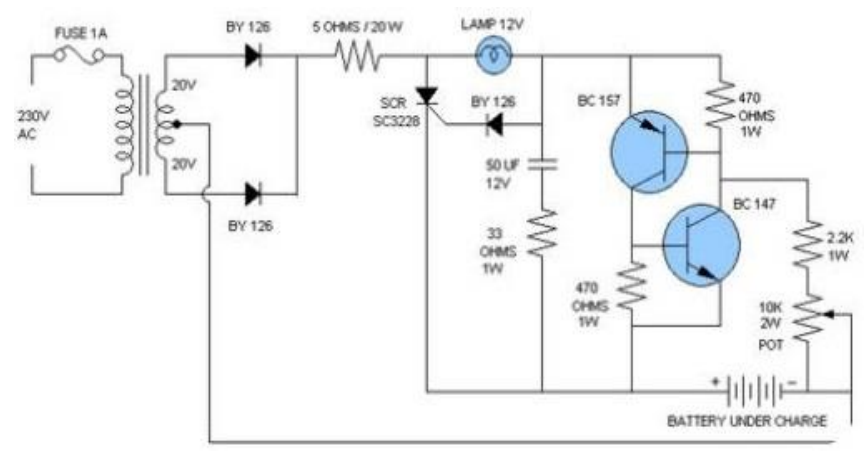

Fig. 4. Charger Circuit Diagram.

A mobile circuit is an electronic circuit specializing in specific electronic circuit elements, transistors, capacitors, inductors, and diodes that are attached by conductive wires or traces that allow current to pass through them. The cylinder, bolt, box, and holder are the most essential components of a door lock, identified by a drawer lock. Knowing how things run in the house is helpful to every DIYer. A volume button was used as an alternative to using the onscreen touch Volume keys to control the phone's volume. This is a volume button program that manages the volume in this system for all forms of volume operations. GSM modem - sim 900 was used also in this project [25].

\section{HARDWARE PART}

Users will compose code and upload it to the Arduino board using the open-source Arduino setting. Java is used to build the environment. The Arduino programming environment is composed of a text editor for code writing, a message area, a text console, a toolbar with main functions, and a series of menus. It attaches to the Arduino hardware, allowing it to upload and interact with programs. $\mathrm{C}$ or $\mathrm{C}++$ is used to write Arduino programs. Arduino capabilities include the ability to compile and upload programs to the Board with only a single command.

The fowling features are present on the board.

1 . The working voltage is 5 volts. 2 . Digital I/O Pins: 14 (with 6 of them supplying PWM), 6. Analog Input Pins for Output: 6, 4. DC Current per I/O Pin: $40 \mathrm{~mA}, 5$. DC 3.3V pin present: $50 \mathrm{~mA}$, DC New 6. DC $3.3 \mathrm{~V}$ pin current: $50 \mathrm{~mA} 6$. 6. Memory flash: $32 \mathrm{~KB}$ of which $0.5 \mathrm{~KB}$ is in use. 7. The boot loader SRAM shall be 2 KB. 8. 1 KB EEPROM, 9. 16 MHz clock speed [26].

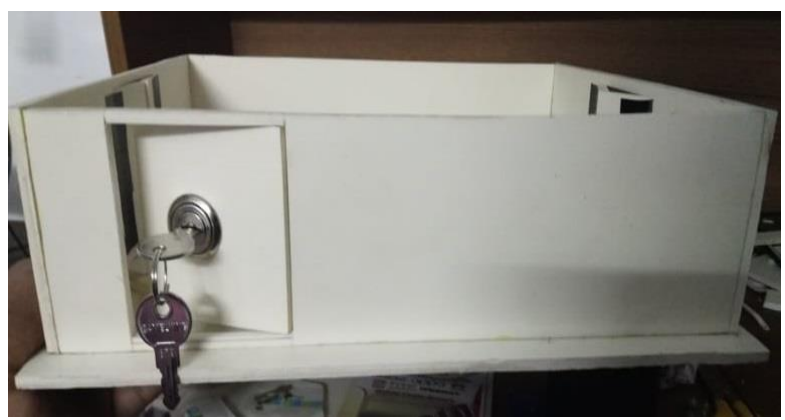

Fig. 5. Lock system and external hardware part of the project.

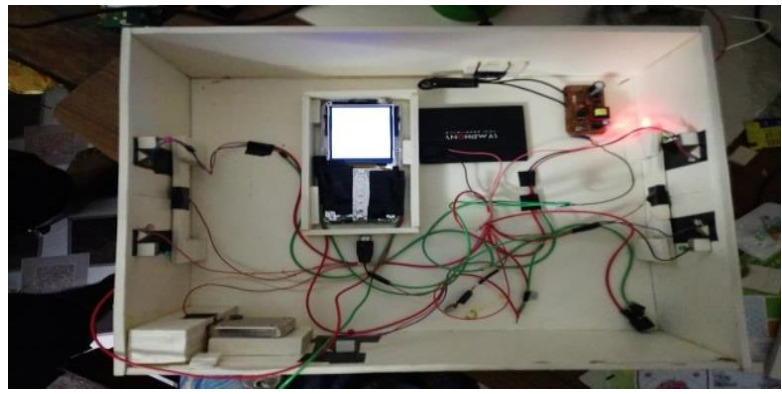

Fig. 6. Internal Hardware part of the Project.

Home mechanization, primary care, and protection framework are the three parts that make up the undertaking's operation. We have planned an android program to manage domestic appliances for home computerization. The use of this program is to give a CALL to our GSM modem. This checks the CALL and transmits it to the microcontroller. The microcontroller extracts the response from the CALL received and activates the relay module. The relay module triggers or disables the equipment in the order of the user. If an interloper flows between the two points, the distance between them will reduce at this point. The distance feedback is relayed to the microcontroller. The microcontroller would send an input SMS to the owner via a GSM modem, and it would also sound an alarm. The benefit of using this safety and protection method is that the basic range at which the caution rings and CALL is sent in client specified, allowing the client to pick any range to which the microcontroller can report [27-29]. 


\section{EXPERIMENTAL RESULTS}

\section{A. The Vibrator System Will Active}

Vibrator System is an active home monitoring system that can be introduced by using central controls to control home devices or equipment that detect various variables using suitable sensors. The key function of such a device is that it gathers parameter data such as temperature, fire, human activity, gas, and so on, and sends the data to a microcontroller or other processor. This controller is designed to transmit command signals to different final controlling devices such as relays, motors, and buzzer devices when certain parameters reach their preset limits.

\section{B. The Alarm System Will Active}

The data from both of these incidents is transmitted to a user's cell phone via a GSM modem. The GSM modem is in charge of transmitting the state of the temperature, lighting, smoke, and other variables to a remote cell phone based on the master microcontroller's commands. It also receives SMS from remote users to monitor items such as lamps, doors, and other household appliances.

\section{The Phone Call Will Active}

The benefit of using this safety and protection device is that the exact range at which the alarm rings and the CALL is sent is user-specified, allowing the user to pick any range at which the microcontroller can report.

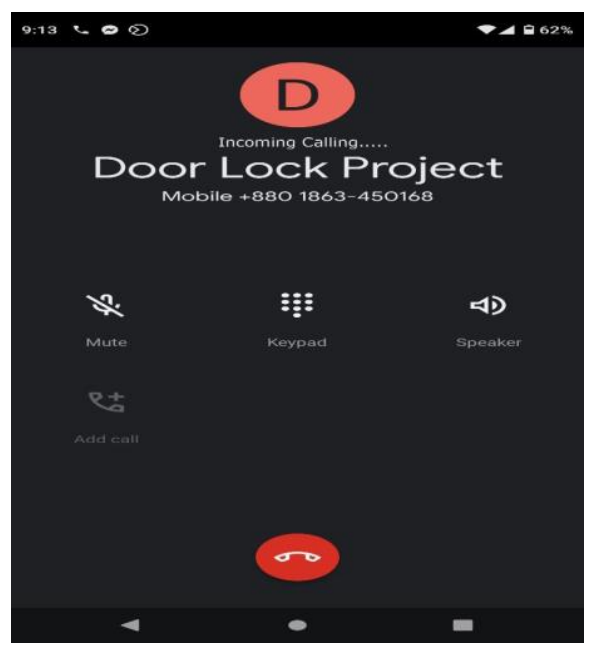

Fig. 7. Calling process on the phone.

\section{CONCLUSION}

We addressed our project on GSM-based home automation, protection, and security system in this article, which is both useful and cost-effective. It offers an easy and quick way to monitor household appliances with only a single SMS or an Android application. The key benefit is that, while the controlling can be achieved by an android application with safety features, it can also be done by sending a daily SMS to the GSM modem if an android phone is not available. Besides, the protection and protection system can be conveniently mounted and used in the home. It notifies the owner in the event of a crash, gas leak, or robbery, even though the owner is not present. The key aim of this study was to design and develop a cost-effective system that used a network-based positioning system to detect the location or movements of vehicles. The primary goal must be believed to have been accomplished. In this work, the key aim was to acquire expertise in the related field of vehicle movement monitoring, gain theoretical and functional knowledge, and culminate in the design and development of a working framework for the intended customer organization, was accomplished.

\section{REFERENCES}

[1] A. W. Ahmad, N. Jan, S. Iqbal and C. Lee, "Implementation of ZigBee-GSM based home security monitoring and remote control system," 2011 IEEE 54th International Midwest Symposium on Circuits and Systems (MWSCAS), Seoul, 2011, pp. 1-4, doi: 10.1109/MWSCAS.2011.6026611.

[2] G. M. S. Mahmud Rana, A. A. Mamun Khan, M. N. Hoque and A. F. Mitul, "Design and implementation of a GSM based remote home security and appliance control system," 2013 2nd International Conference on Advances in Electrical Engineering (ICAEE), Dhaka, 2013, pp. 291-295, doi: 10.1109/ICAEE.2013.6750350.

[3] R. Teymourzadeh, Salah Addin Ahmed, Kok Wai Chan and Mok Vee Hoong, "Smart GSM based Home Automation System," 2013 IEEE Conference on Systems, Process \& Control (ICSPC), Kuala Lumpur, 2013, pp. 306-309, doi: 10.1109/SPC.2013.6735152.

[4] W. M. El-Medany and M. R. El-Sabry, "GSM-based remote sensing and control system using FPGA," 2008 International Conference on Computer and Communication Engineering, Kuala Lumpur, 2008, pp. 1093-1097, doi: 10.1109/ICCCE.2008.4580776.

[5] V. D. Vaidya and P. Vishwakarma, "A Comparative Analysis on Smart Home System to Control, Monitor and Secure Home, based on technologies like GSM, IOT, Bluetooth and PIC Microcontroller with ZigBee Modulation," 2018 International Conference on Smart City and Emerging Technology (ICSCET), Mumbai, 2018, pp. 1-4, doi: 10.1109/ICSCET.2018.8537381.

[6] Huang, Huiping et al. "A remote home security system based on wireless sensor network and GSM technology," 2010 Second International Conference on Networks Security, Wireless Communications and Trusted Computing, Vol. 1, IEEE, 2010.

[7] Parab, Abhishek S., Amol Joglekar, and Abhishek S. Parab. "Implementation of home security system using GSM module and microcontroller." International Journal of Computer Science and Information Technologies, 6.3 (2015): 2950-2953.

[8] Bangali, Jayashri, and Arvind Shaligram, "Design and Implementation of Security Systems for Smart Home based on GSM technology," International Journal of Smart Home, 7.6 (2013): 201208.

[9] Khan, Sadeque Reza et al., "Design and implementation of low cost home security system using GSM network," International Journal of Scientific \& Engineering Research 3.3 (2012): 1.

[10] Sharma, Rupam Kumar et al., "Android interface based GSM home security system." 2014 international conference on issues and challenges in intelligent computing techniques (ICICT, IEEE, 2014.

[11] Choudhury, Biplav, et al. "Design and implementation of an SMS based home security system." 2015 IEEE International Conference on Electrical, Computer and Communication Technologies (ICECCT). IEEE, 2015.

[12] Budijono, Santoso, Jeffri Andrianto, and Muhammad Axis Novradin Noor, "Design and implementation of modular home security system with short messaging system," EPJ Web of Conferences, vol. 68. EDP Sciences, 2014.

[13] Azid, Sheikh Izzal, and Sushil Kumar, "Analysis and performance of a low cost SMS based home security system," International Journal of Smart Home, 5.3 (2011): 15-24.

[14] Lee, Jer-Vui, Yea-Dat Chuah, and Chin-Tin Chai, "A multilevel home security system (mhss)," International Journal of Smart Home, 7.2 (2013): 49-60

[15] Ahmad, Arbab Waheed et al., "Implementation of ZigBee-GSM based home security monitoring and remote control system," 2011 IEEE 54th International Midwest Symposium on Circuits and Systems (MWSCAS), IEEE, 2011.

[16] Ahmad, Shamim et al., "A low SAR in-body antenna for wireless monitoring purpose of pacemaker system," 2019 4th International Conference on Electrical Information and Communication Technology (EICT), IEEE, 2019.

[17] Al Rakib, Md Abdullah, et al., "Design and Simulation-Based Parametric Studies of a Compact Ultra-Wide Band Antenna for 
Wireless Capsule Endoscopy System at Inside Body Environment," International Journal of Electrical and Electronic Engineering \& Telecommunications, 2021.

[18] Al Rakib, Md Abdullah, et al., "Dry and Wet Waste Segregation and Management System," European Journal of Engineering and Technology Research, 6.5, 2021: 129-133.

[19] Al Rakib, Md Abdullah, et al., "Energy Harvesting Technology from Human Motion," 2020 2nd International Conference on Advanced Information and Communication Technology (ICAICT), IEEE, 2020.

[20] Mahamud, Md Sadad, et al., "Mouchak-An IoT Basted Smart Beekeeping System Using MQTT," 2019 4th International Conference on Robotics and Automation Engineering (ICRAE), IEEE, 2019.

[21] Mohaiminul Islam, et al., "Effects of interionic pair interactions on atomic transport properties of liquid Al", Indian Journal of Physics, pp. 1-10, Springer India, 2021.

[22] Fysol Ibna Abbas, et al., "Critical Properties of Segregation for $\mathrm{Al}_{1-\mathrm{x}} \mathrm{Bi}_{\mathrm{x}}$ Liquid Binary Alloys", Journal of the Physical Society of Japan, vol. 89, issue 11, pp. 114004, The Physical Society of Japan 2020.

[23] N. E Dubinin, et al., "Effective Wills-Harrison Pair Interaction in Liquid Au", Russian Metallurgy (Metally), vol. 2019, Issue 8, pp. 835837, 2019.

[24] G.M. Bhuiyan, et al., "Local minimum in pair potentials of polyvalent metals: A limitation of pseudopotential theory", International Journal of Modern Physics B.

[25] Fysol Ibna Abbas, "Thermodynamic and transport properties of aluminium (Al)-based liquid binary alloys: Research work for Sustaining developing alloys for energy sector", Department of Theoretical Physics, University of Dhaka, (2019).

[26] Fysol Ibna Abbas, et al., "A study of thermodynamics of mixing for $\mathrm{Al}_{1-\mathrm{x}} \mathrm{Sn}_{\mathrm{x}}$ liquid binary alloy", Journal of non-crystalline solids, vol. 481, pp. 391-396, Publisher North-Holland (2018)

[27] Fysol Ibna Abbas, et al., "Energy of mixing and entropy of mixing for $\mathrm{Cu}_{\mathrm{x}} \mathrm{Al}_{1-\mathrm{x}}$ liquid binary alloys", arXiv preprint arXiv:1607.05827, (2016).

[28] S. Ahmad et al., "Design of a Compact Simple Structural Dual-band Patch Antenna for Wireless On-body Medical and Sports Devices," 2021 2nd International Conference on Robotics, Electrical and Signal Processing Techniques (ICREST), IEEE, p 577-581, (2021).

[29] Al Rakib, Md Abdullah, et al., "An Arduino Based Smart Hand Gloves for Load Control and Physician Notification," 2021 International Conference on Automation, Control and Mechatronics for Industry 4.0 (ACMI), IEEE, p 1-.5, (2021)

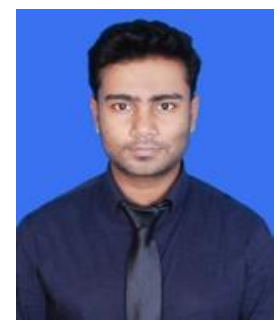

Md Abdullah Al Rakib received Bachelor of Science (B.Sc.) in EEE from American International University-Bangladesh (AIUB). He started his career in September 2018 at City University-Bangladesh (CUB) as Lecturer in the Dept. of EEE. His research interest is focused on Power, electronics, IoT, and Telecommunication.

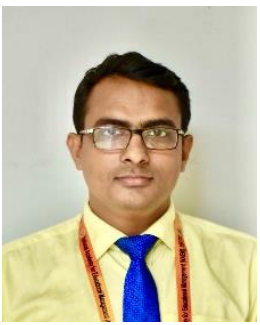

Md. Moklesur Rahman received his M.Sc. in Physics from Dhaka University, Bangladesh in 2012 and B.Sc. in Physics from Dhaka University, Bangladesh in 2011. He joined as the BCS Education cadre in 2016 . He is currently working as a Lecturer in the Department of Physics, Shahzadpur Govt. College, Sirajganj, Bangladesh. He has more than 5 years of experience in teaching and research. His research interests are in Material Physics, IoT and Condensed Matter Physics.

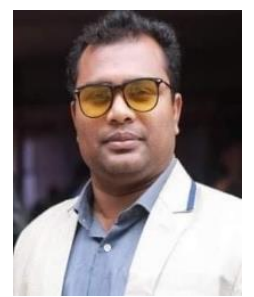

Md. Sohel Rana has completed his undergraduation degree (B.Sc.) \& graduation degree (M.Sc.) in Physics from Department of Physics, University of Dhaka. He is currently studying on biomedical physics as M. Phil at the department of Biomedical Physics under the program offer from national university, Bangladesh. He started his career at Tejgaon college, Dhaka-1215, in 2018 as a Lecturer in physics at the department of physics. Physics, electronics, IoT.

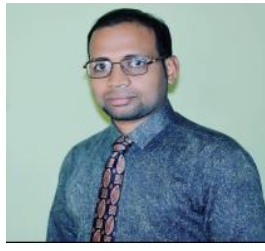

Md. Sanjib Islam received Bachelor of Science (B.Sc.) in EEE from Independent University, Bangladesh (IUB). He started his career September 2018 at IUB as a EEE researcher. His research interests are focused on Power, electronics, IoT \& Electronics.

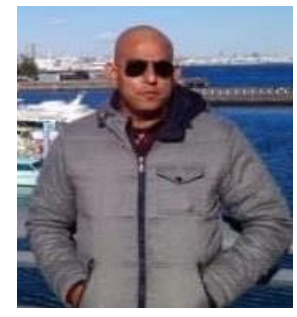

Dr. Fysol Ibna Abbas received his Ph.D. in Material science of Engineering from the collaboration work between University of Dhaka (Bangladesh) \& IIT (Indian Institute of Technology) Kharagpur, India in 2019. He completed his M.Sc from the Department of Theoretical Physics (Condensed Matter Research Group) at the University of Dhaka in 2012. From the same university, he completed his B.Sc in Physics (2010). He is currently working as an active researcher at the Graduate school of science, Tokyo Metropolitan University at Chofu shi, Tokyo prefecture, Japan. In his service career, he served as an Assistant Professor in the Department of Electrical \& Electronic Engineering, City University Bangladesh (CUB) from 2018 to 2021. He has also served as a faculty member in the MNS Department at BRAC University from 2014 to 2018 . He has more than 12 years of experience in teaching and research area of engineering. His research interests are focused on High entropy alloys (HEA), Liquid binary alloys, Thermoelectric materials (TE), Functional materials application, Superconductivity (SC), Nanotechnology, Solar cell and Optics. 